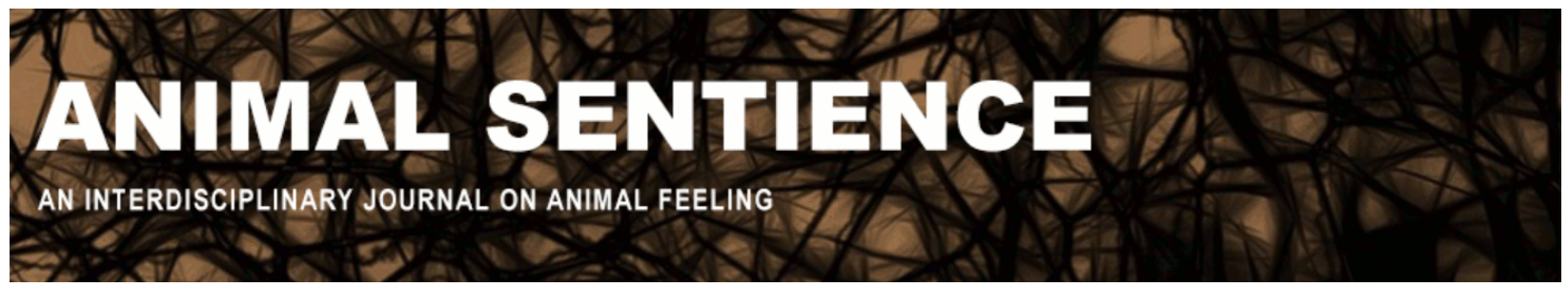

Gygax, Lorenz and Nawroth, Christian (2019) Farm animals are not humans in sheep clothing. Animal Sentience 25(25)

DOI: $10.51291 / 2377-7478.1461$

Date of submission: 2019-05-27

Date of acceptance: 2019-06-04 (c) 


\title{
Farm animals are not humans in sheep clothing
}

Commentary on Marino \& Merskin on Sheep Complexity

\author{
Lorenz Gygax \\ Albrecht Daniel Thaer-Institute of Agricultural and Horticultural Sciences \\ Humboldt Universität zu Berlin \\ Christian Nawroth \\ Institute of Behavioural Physiology \\ Leibniz Institute for Farm Animal Biology
}

\begin{abstract}
Research on the mental lives of farm animals is crucial to assess not only their physical but also their psychological wellbeing. Their current housing and handling practices are highly unlikely to meet their cognitive needs and demands, but our knowledge of their mental capacities is still limited. Although folk wisdom often refers to farm animals as dull and inflexible, recent studies show they have a rich interpretation of their environment and can solve complex problems. Yet an uncritical and anthropomorphic assessment of farm animal cognition and behaviour may lead to the attribution of an exaggerated amount of cognitive flexibility. Contrary to what Marino \& Merskin intended, the approach of assessing their intelligence can have detrimental consequences both for animal welfare and for science in general.
\end{abstract}

Lorenz Gygax was trained as an ethologist and has worked in welfare science for over 15 years. He studies how behaviour is controlled and how this control links to emotional states. He is currently in the research group of Animal Husbandry and Ethology at Humboldt Universität zu Berlin. Website

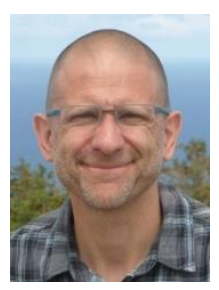

Christian Nawroth, currently a postdoc at the Leibniz Institute for Farm Animal Biology, studies how farm animals perceive and interact with their physical and social environments and how this knowledge can be used to improve management conditions and human-animal interactions. Website

Marino \& Merskin (2019; M\&M) nicely summarise research on sheep cognition, personality, emotion, and social structure. Their review follows their previous work that has focused on pigs (Marino \& Colvin 2015), chickens (Marino 2017) and cows (Marino \& Allen 2017). It will surely be a valuable resource for students and scholars navigating through the growing literature on cognitive behavioural studies in sheep and other farm animals. While it is laudable to accumulate evidence on the emotional and cognitive lives of sheep - animals that often have a (false) reputation for being unintelligent and inflexible - the way M\&M realise this task lacks scientific rigor. 
Most sections in M\&M's review share a similar structure: They start out with a wellestablished human phenomenon (the "what") and its potential corresponding interpretation (the "how"). They proceed to refer to studies that have observed similar (behavioural) patterns in animals for which an interpretation in terms of higher mental capacities is widely accepted (such as, e.g., primates, elephants, or dolphins). They continue referring to the relatively small number of studies in sheep that have investigated a similar phenomenon (the "what"), concluding that the similar "what" equals a similar "how" found in humans. This reasoning by analogy is a tool that is often used in science. But it can be highly problematic in the interpretation of results from purely behavioural data and the consequences that might arise from these over-interpreted claims (Horback 2019). In addition, a smart sheep might need capacities that are completely different from those in humans (Adolphs 2019, Figdor 2019, Pellis 2019).

For a valid assessment of the cognitive capacities of farm animals, a critical evaluation of the existing studies is mandatory. In this research area, like any other, we should not take the results of a single study describing a new phenomenon at face value. Cherry-picking - that is, reporting biased towards positive (or negative) results (or in case of ambiguous results, arguing in favour of positive results) - leads to the simplification and over-interpretation of the phenomena observed (Vonk 2019). Nor are anthropomorphic comparisons useful either when assessing cognition, emotions and personality in farm animals (Hill 2017). Currently, we know too little to make any judgment on whether most phenomena we observe in animals rely on the same mechanism as in humans (see, e.g., Heyes 2015, Wechsler 2019). A critical assessment also entails not over-stating hypotheses such as that sheep, like humans, non-human primates or dolphins possess similar forms of higher cognitive functions (Towler et al. 2019).

It is true that recent advances in studies on farm animal cognition (Nawroth et al. 2019) indicate that that they have some complex cognitive capacities - a line of argument that does not reflect their public reputation. But biased reporting and a lack of critical assessment of the results of cognitive studies can do more harm than good, for example, when we attribute a degree of behavioural flexibility to animals that they do not possess. This can diminish their welfare: We might falsely infer an increased ability to cope with a novel, potentially stressful situation. Or we might provide animals with enrichment which is not suited for their behavioural and cognitive repertoire. Handling and training principles should be based on the actual mental capacities of the species in question because it can otherwise lead to increased frustration and stress (Rorvang et al. 2018). Over-interpreting the intelligence of farm animals can thus have detrimental consequences for their wellbeing in the long-term.

The issues raised above may have an even broader implication for science. The ability or inability to replicate any given study is the basis of how science progresses. New ideas and hypotheses often arise based on single studies, with subsequent research focusing on the same phenomenon. The follow-up studies may attempt to replicate the original study or may investigate the phenomenon in a different context. The novel idea from the original study can then be supported or refuted (e.g., Amrhein et al. 2019). This is how science progresses: in slow and error-prone steps, probing many dead ends along the way. If we first overstate the relevance and meaning of single studies, which may need to be dismissed or retracted later, this is a disservice science in general, as the public perceives such retractions nowadays as a fault rather than an integral part of science (Shrout \& Rogers 2018). 
It is for these two lines of argument - for the sake of animal welfare and for the sake of science in general - that we would like to call for critical and realistic interpretations of studies on any cognitive capacity in animals. This does not mean that we cannot be cautious in our political and ethical decisions, basing them on the assumption that animals might indeed have higher mental states and capacities "to be on the safe side". Such a precautionary stance (Birch 2017), however, needs to be clearly distinguished from what we may consider a scientific fact.

\section{References}

Adolphs, R. (2019). Using sheep psychology to guide sheep policy. Animal Sentience 25(14).

Amrhein, V., Greenland, S., \& McShane, B. (2019). Scientists rise up against statistical significance. Nature 567, 305-307.

Birch, J. (2017). Animal sentience and the precautionary principle. Animal Sentience 16(1).

Figdor, C. (2019). The mental lives of sheep and the quest for a psychological taxonomy. Animal Sentience 25(16).

Heyes, C. (2015). Animal mindreading: What's the problem? Psychonomic Bulletin \& Review 22(2), 313-327.

Hill, H. M. (2017). The psychology of cows? A case of over-interpretation and personification. Animal Behavior and Cognition 4(4), 506-511.

Horback, K. (2019). Applied cognition research to improve sheep welfare. Animal Sentience 25(18).

Marino, L. (2017). Thinking chickens: A review of cognition, emotion, and behavior in the domestic chicken. Animal Cognition 20(2), 127-147.

Marino, L., \& Allen, K. (2017). The psychology of cows. Animal Behavior and Cognition 4(4), 474498.

Marino, L., \& Colvin, C. M. (2015). Thinking pigs: A comparative review of cognition, emotion, and personality in Sus domesticus. International Journal of Comparative Psychology 28.

Marino, L., \& Merskin, D. (2019). Intelligence, complexity, and individuality in sheep. Animal Sentience 25(1).

Nawroth, C., Langbein, J., Coulon, M., Gabor, V., Oesterwind, S., Benz-Schwarzburg, J., \& von Borell, E. (2019). Farm animal cognition: Linking behaviour, welfare and ethics. Frontiers in Veterinary Science 6, 24.

Pellis, S. M. (2019). Guilty as charged. Animal Sentience 25(19).

Rørvang, M. V., Christensen, J. W., Ladewig, J., \& McLean, A. (2018). Social learning in horsesfact or fiction? Frontiers in Veterinary Science 5, 212.

Shrout, P. E., \& Rodgers, J. L. (2018). Psychology, science, and knowledge construction: Broadening perspectives from the replication crisis. Annual Review of Psychology, 69, 487510.

Towler, A., Kemp, R. I., Bruce, V., Burton, A. M., Dunn, J. D., \& White, D. (2019). Are face recognition abilities in humans and sheep really 'comparable'?. Royal Society Open Science 6.

Vonk, J. (2019). Pulling the wool from our eyes. Animal Sentience 25(3).

Wechsler, B. (2019). Three levels of consciousness: A pattern in phylogeny and human ontogeny. International Journal of Comparative Psychology 32. 